\title{
Unpacking the Complexity of Life Events and Desistance: An Application of Conjunctive Analysis of Case Configurations to Developmental and Life Course Criminology
}

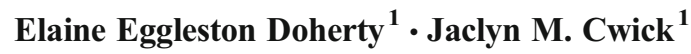

Received: 30 August 2015 /Revised: 14 November 2015 / Accepted: 15 December 2015 /

Published online: 7 January 2016

(C) Springer International Publishing AG 2016

\begin{abstract}
Purpose The present study applies a case-oriented method, the conjunctive analysis of case configurations (CACC), previously used in criminal event research to life course criminology. In this application, we use CACC to address whether and how "context" matters for desistance by constructing complex role configurations of life events, their timing, and their ordering and examining their influence on desistance.

Methods Longitudinal life event and official offending data are drawn from a community cohort of African American males and females. Using CACC, we focus on (1) identifying the most common role configurations of number, timing, and ordering of life events in the sample (i.e., the dominant case configurations); (2) testing main effect hypotheses of each measure; and (3) exploring potential interaction effects. The findings from the CACC are then used to inform a logistic regression model to statistically test for the identified main and interactive effects.

Results First, the dominant case configurations are largely ones that are "off time" and "out of order." Second, there is a main effect of dosage in that those experiencing four life events were more likely to desist than those with two life events. Finally, CACC revealed a potential three-way interaction effect among the number, timing, and ordering of life events on desistance, which was confirmed by the logistic regression analysis.

Conclusions CACC is a useful tool for teasing out the complex relationships inherent in life course criminological questions. Several additional life course research questions where CACC could be used are discussed.
\end{abstract}

Electronic supplementary material The online version of this article (doi:10.1007/s40865-015-0023-0) contains supplementary material, which is available to authorized users.

Elaine Eggleston Doherty

dohertye@umsl.edu

1 Department of Criminology and Criminal Justice, University of Missouri - St. Louis, 324 Lucas Hall, St. Louis, MO 63121, USA 
Keywords Life events $\cdot$ Desistance $\cdot$ Life course principles

\section{Introduction}

There are several basic principles inherent in the life course perspective. One core principle is that lives are shaped by multiple long-term trajectories (e.g., family, career, health, offending, etc.), and embedded within these long-term trajectories are transitions (i.e., short-term discrete life events) that can redirect any of these trajectories [4]. With respect to crime, life events such as school completion, employment, marriage, and parenthood have been found to have the potential to redirect one's offending trajectory and facilitate desistance. In fact, life course criminological research is replete with studies that show that individual life events impact desistance from offending among a wide variety of samples and historical time periods (see [36] for a review). However, at this point, our understanding of desistance needs to extend beyond the question of whether an individual life event can impact desistance. That is, discrete transitions (or life events) do not always become "turning points" that redirect a trajectoryleaving the question of, what might condition this effect?

Over 20 years ago, there was a call to consider and better understand the heterogeneity in outcomes in the presence of the same life transition based on historical and social context [6]; see also [17,34]. Although there have been great strides made in the stress literature with respect to coping strategies and factors such as social support as buffers in the presence of stress (see e.g., [38]), this variability within life event categories has not been systematically studied in life course criminology beyond the quality of the life event $[16,34]$. Indeed, the notion that "context matters" when experiencing a discrete life event is also a core principle of life course research, with context representing any number of elements that can shape one's developmental trajectory. Yet, the question remains: Are there certain identifiable and measurable conditions or contingencies (i.e., "contexts") that make it more likely for an individual life event-school completion, employment, marriage, or parenthood - to lead to desistance? Here, we take into account three aspects of an individual's social context by considering the accumulation of numerous life events, the timing of life events, and/ or the ordering of life events [5].

With respect to the number of life events (i.e., dosage), research has found that experiencing multiple life events facilitates desistance more than experiencing onealso known as experiencing the "respectability package." Moreover, research indicates that the importance of dosage is particularly apparent among African Americans [7]: 1013; see also [40]. The idea that the timing of transitions can affect future success in life domains has also been supported in the extant literature with desistance being more evident among those who experience life events in a "normative" or "on time" pattern $[37,39]$. Finally, researchers have highlighted the dispersion and sequencing of life events when predicting outcomes. In these explanations, the "normative" or "in order" sequence of life events such as the timing of marriage relative to finishing school, obtaining a job, and/or parenthood is found to impact the success of adult outcomes (see e.g., $[12,13,33])$.

As MacMillan [21] states, "understandings of the life course in general, as well as the antecedents and consequences of discrete roles, are thus enhanced by a consideration of 
more general matrices of roles, what might be called role configurations, their timing in the life span, and the pathways through life that their dynamic unfolding reveals" (see also [22]). Thus, a more holistic approach is needed to understand how the configurations of dosage, timing, and ordering impact desistance from criminal offending. One technique, the Conjunctive Analysis of Case Configurations (CACC), has the capacity to model these complex role configurations of life events and relate them to desistance outcomes.

Specifically, we collectively consider the dosage (i.e., number), ordering, and timing of four life events - high school graduation, employment, marriage, and parenthoodon desistance from crime. Through this illustration we seek to (1) address the substantive questions under study but also to (2) introduce a potentially useful methodology to life course criminologists interested in unpacking the complexities inherent in predicting the heterogeneity in desistance and other social behaviors over the life course.

\section{Conjunctive Analysis of Case Configurations}

First introduced to criminology by Miethe and colleagues [24], CACC represents "an alternate template" to understanding social problems (see [30]). In short, CACC is a case-oriented approach that identifies unique combinations of variable attributes resulting in "a visual representation of the data that is easily interpretable" so that results reveal patterns in the data that are often "masked by more traditional analytic approaches such as multivariate main-effects regression models" ([9]: 9). This method has the capacity to summarize the data in a way that allows for a better understanding of the complex combinations of attributes that occur within each criminal event or, in its application to life course criminology, within each individual. Examination of the resulting case configurations then allows for a focus on (1) exploring the patterns in the data to identify the dominant case configurations; (2) analyzing specific case-oriented hypotheses; and (3) exploring potential interaction effects.

Originally used as an exploratory method, Miethe and colleagues [24] provide a thorough description of CACC as well as its capacity to go beyond its exploratory origins. Several researchers have since used CACC to better understand how the convergence of victim, situational, and crime characteristics predicts criminal events through an examination of the various configurations of these characteristics. For instance, researchers have used CACC along with measures of central tendency and dispersion to identify "normative" and deviant case configurations to examine the contextual effects of reporting crime to the police (e.g., [31, 32]). Others have incorporated traditional regression to provide guidance for CACC variable selection/ inclusion when examining sentencing disparities (e.g., [11, 19]), while others use tests of statistical significance to support CACC-identified effects to better illustrate situational influences on sentencing decisions (e.g., [24]). Using these techniques associated with CACC, researchers have sought to understand these criminal justice issues as well as gun use by offenders and victims [9, 18], sexual assault events [23], bullying [8], and violence against college students [10] among others.

While the similarities between event-based research of criminal incidents and life course research of individuals may not be immediately obvious to some, one core similarity is that life course research also seeks to simultaneously consider the combination 
of multiple variable attributes within certain units with respect to a specific outcome [4]. Thus, as applied to the outcome of desistance, CACC represents an innovative direction to model the variability in the discrete life events that impact long-term trajectories over time and allows for a consideration of the combinations of life course attributes that create "context".

The current study extends the existing literature on the independent effects of life events by adopting the CACC approach to explore how various configurations of four key life events (i.e., high school graduation, employment, marriage, and parenthood), their timing ("on time" vs. "early" or "late"), and their ordering ("in order" vs. "out of order") influence the relative likelihood of desistance from criminal offending. This focus on the unique case configurations of multiple life events, their timing, and their ordering will help us to better understand whether and how contextual factors of life events influence the stability and change in crime over the life course. To this end, we draw on existing interview and criminal history data from a community cohort of African American males and females from the Woodlawn neighborhood of Chicago who were interviewed at ages $6,16,32$, and 42 and whose criminal histories span ages 17 to $52[2]$.

\section{Methods}

\section{Data}

The data for this application of CACC come from the Woodlawn study, which is a prospective, longitudinal study of an epidemiologically defined cohort of 1242 first graders, initiated in 1966-67 (51.2\% males), who attended one of the nine public and three parochial schools in Woodlawn, a community on the Southside of Chicago. The cohort of first graders was followed-up in adolescence (ages 16-17), in early adulthood (ages 32-33), and most recently in mid-adulthood (ages 42-43). The initial sample included virtually all children within the first grade classrooms in the Woodlawn community resulting in little selection bias based on nonparticipation (only 13 families declined participation).

The adult interviews (age 32 and age 42) and the official criminal histories are used in the current study. When the participants were age $32,80 \%(n=952)$ of the original living cohort were located and interviewed about a variety of social, psychological, and behavioral domains. In 2002, $72 \%(n=833)$ of the living participants were interviewed using a similar interview schedule to the age 32 interview. The criminal history information is drawn from the Chicago Police Department and the Federal Bureau of Investigation criminal records obtained in 1993, which spanned the age of majority (age 17 in Illinois) to age 32 . These criminal histories were recently updated to age 52 using records from the Illinois State Police and the Illinois Criminal Justice Information Authority. The data provide the number of offense counts for each individual at each age between 17 and 52. ${ }^{1}$ Throughout the study, reports of mortality have been gathered

\footnotetext{
${ }^{1}$ The charge data includes up to three unique and most serious charges to provide an accurate account of offending and to err on the conservative side. It should be noted that $99 \%$ of the arrest entries had three or fewer charges per arrest (91\% had only one charge) (see [2]).
} 
from family members and neighbors as well as through searches of the National Death Index, with the most recent search conducted in 2009 ( $n=132$ dead as of $2009,11 \%$ of the original cohort).

\section{Final Sample}

The original cohort was 1242 men and women yet 8 had died by age 17 leaving a starting sample size of 1234 for this study. We removed 17 individuals who had conflicting self-report and criminal justice information (e.g., self-reported being incarcerated for more than 6 months at the age 32 interview yet had no arrest record), which left a sample of 1217 individuals with valid criminal history information from ages 17 to 52. Next, we reduced the sample with criminal history data to include all respondents who also had an adult interview $(n=1043)$ as this was the source of data for the life event information. Finally, in order to take ordering into account, we included only those who experienced at least two life events by age 42, resulting in a final sample of 983 (79.1\% of the original cohort; $53.4 \%$ women, and $46.6 \%$ men). ${ }^{2}$

\section{Measures}

\section{Criminal Desistance}

The outcome of interest, criminal desistance, is operationalized using a group-based trajectory method to model the long-term patterns of total offense counts from ages 17 to 52. These total offense counts include any violent (e.g., homicide, assault, rape, robbery), property (e.g., burglary, larceny, auto theft, fraud, criminal damage), drug/alcohol (e.g., narcotics, both selling and possession, driving under the influence) or other offense (e.g., public order crimes, non-violent sex crimes, weapons offenses) at each age. We exclude all traffic offenses. Mortality and sentencing information were integrated into the longitudinal criminal histories to safeguard against presuming someone had stopped offending who had instead died or was incarcerated. ${ }^{3}$

To determine which offenders follow a desistant as opposed to persistent trajectory throughout adulthood, we employ the group-based semiparametric mixed Poisson model, which estimates the predicted number of offenses per year at each age for each trajectory group. The semiparametric mixed Poisson model [14, 26, 27] assumes that the population is comprised of discrete Poisson distributions with a $\lambda$ rate of offending resulting in a number of different groups of individuals who demonstrate similar patterns of offending over time. Each developmental trajectory assumes a cubic relationship that links age and offending ([27]: 33). This type of method is specifically designed to identify and depict discrete groups of individuals who are homogenous in

\footnotetext{
${ }^{2}$ Six men and four women experienced zero life events and 35 men and 15 women experienced only one life event.

${ }^{3}$ The inclusion of days incarcerated would be ideal to safeguard against underestimating the actual level of offending in any given year [3, 29]. Unfortunately, we do not have the exact number of days incarcerated at each age. As a proxy, we incorporate the sentencing data from the arrest records into the criminal histories such that each individual is considered incarcerated in any year that he or she has zero offenses and is known to have been sentenced to more than 1 year in prison at that age.
} 
their behavior within their trajectory yet distinct from those following other trajectories (e.g., those who persist through adulthood versus those who desist).

Using key model diagnostics (e.g., the Bayesian Information Criterion, odds of correct classification, posterior probabilities), we determined that the five-group model best fit the data [27]. ${ }^{4}$ Based on the trajectory groups depicted in Fig. 1, we identified 619 individuals as non-offenders and 364 as offenders. Among the offenders, we combined the high-rate and low-rate groups of desisters and the high-rate and low-rate groups of persisters depicted in Fig. 1. Thus, we identified 267 as desisters (coded "1") and 97 as persisters (coded " 0 "). ${ }^{5}$

\section{Contingencies of Life Events}

In line with the use of binary indicators in conjunctive analysis, we coded each indicator as binary to represent the presence or absence of each factor. First, we coded four separate variables indicating whether or not each cohort member experienced high school graduation (not including GED completion), reported ever having a steady job (employed for six months or longer), reported ever being married, and ever being a parent (i.e., a biological parent). The vast majority of the full sample of 983 respondents and 364 offenders experienced a first steady job (98.5 and $98.9 \%$, respectively) and had a child ( 84.5 and $89.8 \%$, respectively). In contrast, the offenders were less likely to graduate from high school than the full sample (47.5 and $65.8 \%$, respectively) and close to $60 \%$ of both samples marry (58.5 and $62.5 \%$, respectively).

If a person experienced a life event, we then coded additional variables indicating the age when this first occurred. Thus, we coded a person's age at high school graduation, age of first steady job, age of first marriage, and age when first child was born. ${ }^{6}$ Timing of these life course events indicates whether all life events occurred "on time" or whether at least one diverges from the sample "norm," defined as within one standard deviation of the mean age of each event. Those who experienced all of their life events within one standard deviation above or below the mean age of the full sample were coded "on time" ("1"). Individuals who experienced any life event at either an older or younger age (i.e., more than one standard deviation above or below the mean) were coded as "off time" ("0"). ${ }^{7}$

Ordering gauges whether the life events experienced by each respondent occurred in the "normative" or socially expected order or not. Here, we define "normative" sequencing of life events to be high school graduation, followed by the acquisition of

\footnotetext{
${ }^{4}$ Although the BIC continued to decrease past 5 groups, the average posterior probability in one group in the 6-group model fell to close to 0.75 . The average posterior probabilities in the 5 -group model ranged from 0.918 to 0.973 , the odds of correct classification were all over 5 , and the population and sample proportions were very similar (within a 0.7 difference or smaller) (diagnostic data available upon request).

${ }^{5}$ Although we ideally wanted to compare the high-rate and low-rate desisters vs. persisters separately, the sample sizes of these groups precluded this type of analysis.

${ }^{6}$ It should be noted that although there is an overlap between the trajectories, which include ages 17 to 52 , and the life events, which can occur anytime in adulthood, this overlap is assumed to be minimal. On average, all of the life events occur in the late teens and early 20 s (i.e., in the first quarter of the trajectory) (see Table 1) and for 3 of the life events, $89.7 \%$ occurred by age 30 . The exception to this is marriage where $73.7 \%$ of those married did so by age 30 .

${ }^{7}$ We use the mean age of the full sample as opposed to the offender sample to establish the "normative" age when each life event typically occurs for the cohort as a whole.
} 


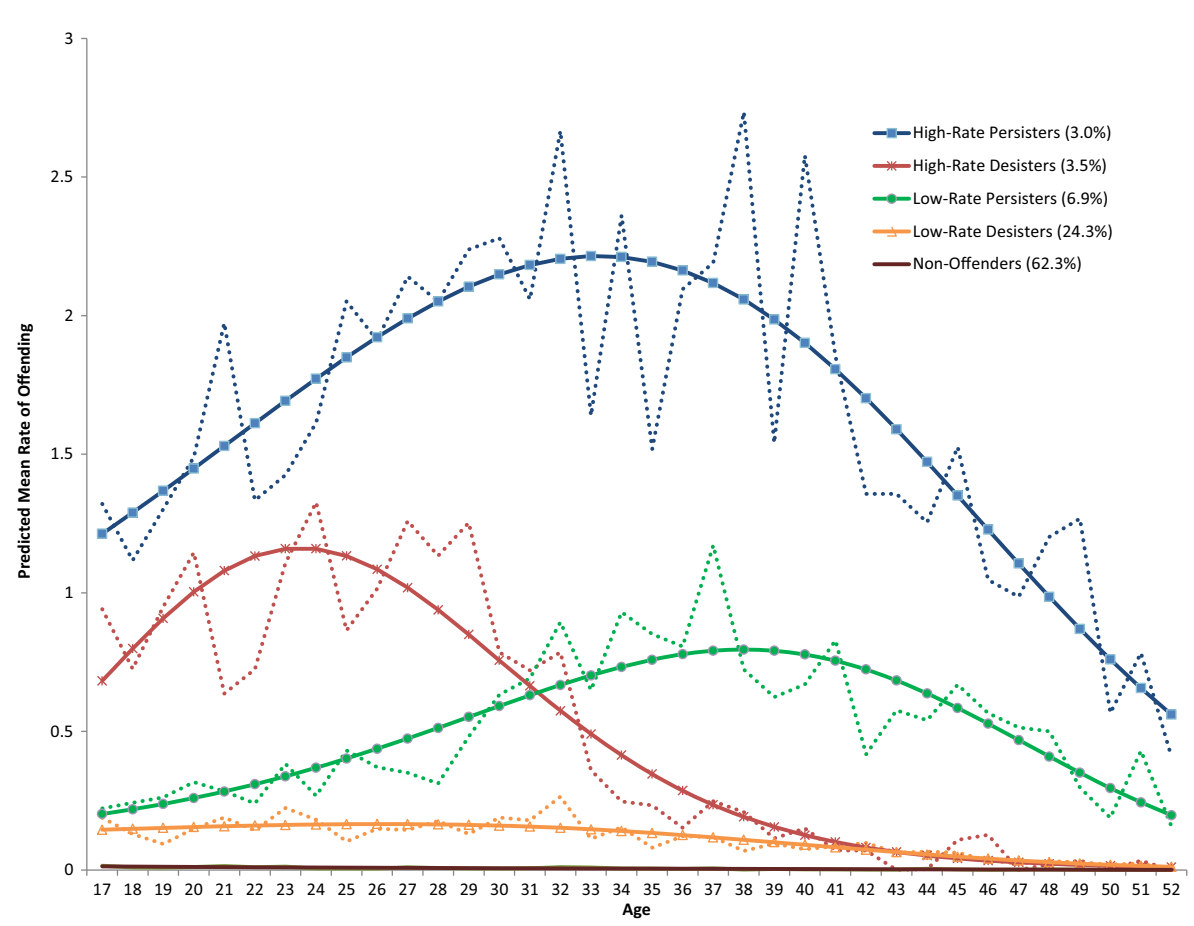

Fig. 1 Trajectories of offending for Woodlawn males and females $(n=983)$

one's first steady job, followed by marriage, and finally, the birth of their first child ([21]; see also [6]). When life events follow this "normative" pattern, we coded them as "in order" ("1"). Because the ordering of life events is based on whole ages, multiple life events often occurred at the same age. Thus, someone coded as having experienced their life events in order may include a tie between consecutively sequenced events (i.e., high school graduation and first steady job). However, if a tie occurred between two non-consecutive events (i.e., between high school graduation and birth of a first child and other life events were experienced before or after) then these events would be coded "out of order."

\section{Analytic Strategy and Results}

We outline our analyses similar to that of Miethe and colleagues [24] discussion of CACC with regard to criminal events to best display how this technique can be applied to life course criminology. ${ }^{8}$ Therefore, after presenting some descriptives, we intertwine the CACC analytic strategy with the results of our three research questions: (1) what are the dominant case configurations in our data?; (2) do the dosage, timing, and ordering combinations predict desistance from crime, as predicted by life course principles?; and (3) are there any interaction effects between these potential contingencies of life events (i.e., dosage, timing, and ordering) in predicting desistance? We then conduct a

\footnotetext{
$\overline{{ }^{8} \text { For syntax coding to run CACC }}$ models in a variety of statistical packages, please refer to Miethe et al. [24]. The CACC analyses in this study were conducted in SPSS version 21.
} 
multivariate logistic regression analysis to determine if the main effects and interactive effects identified through the conjunctive analyses are statistically significant in this more traditional analysis, while controlling for key correlates of offending.

\section{Descriptives}

A summary of descriptive statistics with respect to the dosage, timing, and ordering of the four life events examined in this study for both the full sample of 983 respondents and the 364 offender sample can be found in Table 1. For the full sample, the number of life events is fairly evenly distributed with $36.6 \%$ experiencing four life events, $37.5 \%$ experiencing three life events, and $25.8 \%$ experiencing two life events. This is in contrast to the offenders who have more of an inverted U-shaped distribution with $26.4 \%$ experiencing all four life events, $42.0 \%$ experiencing three life events, and $31.6 \%$ experiencing two life events. However, for both samples approximately $45 \%$ experienced all of their life events on time and $35 \%$ experienced their life events in order.

The temporal distribution of these life events is fairly similar for the full sample and the offending sample. The average span of time between the first and last life event is

Table 1 Summary statistics of dosage, timing, and ordering of life events

\begin{tabular}{|c|c|c|}
\hline & $\begin{array}{l}\text { Full sample } \\
(n=983)\end{array}$ & $\begin{array}{l}\text { Offenders } \\
(n=364)\end{array}$ \\
\hline \multicolumn{3}{|l|}{ Dosage } \\
\hline 2 life events & $25.8 \%$ & $31.6 \%$ \\
\hline 3 life events & $37.5 \%$ & $42.0 \%$ \\
\hline 4 life events & $36.6 \%$ & $26.4 \%$ \\
\hline Timing $(1=$ on time $)$ & $43.6 \%$ & $44.8 \%$ \\
\hline Average age of life event-all & 22.31 & 22.38 \\
\hline HS grad & 18.41 & 18.45 \\
\hline First steady job & 22.45 & 22.19 \\
\hline First marriage & 26.02 & 26.50 \\
\hline Birth of first child & 22.49 & 21.72 \\
\hline difference between age at oldest and youngest life event & 9.39 & 9.05 \\
\hline all events within 2 years of each other & $13.2 \%$ & $13.7 \%$ \\
\hline all events within 5 years of each other & $31.4 \%$ & $34.6 \%$ \\
\hline Ordering $(1=$ in order $)$ & $35.6 \%$ & $33.5 \%$ \\
\hline Most common among those with 2 events & $n=254$ & $n=115$ \\
\hline full sample: children, steady job, no other events $(n=64)$ & $25.2 \%$ & \\
\hline offenders: children, steady job, no other events $(n=41)$ & & $35.6 \%$ \\
\hline Most common among those with 3 events & $n=369$ & $n=153$ \\
\hline full sample: children, marriage, steady job, no HS grad $(n=44)$ & $11.9 \%$ & \\
\hline offenders: steady job, children, married, no HS grad $(n=27)$ & & $17.6 \%$ \\
\hline Most common among those with 4 events & $n=360$ & $n=96$ \\
\hline full sample: high school, steady job, married, children $(n=43)$ & $11.9 \%$ & \\
\hline offenders: high school, steady job, children, married $(n=11)$ & & $11.4 \%$ \\
\hline
\end{tabular}


approximately 9 years with nearly one-third (31.4\% and $34.6 \%$, respectively) of the sample experiencing all their life events within a period of five years. With respect to ordering, a total of 91 unique sequences are present within the full sample and 67 unique sequences in the offender sample. For both the full sample and offenders who experienced two life events, the most common sequence of those life events is the out of order sequence of birth of first child followed by first steady job with no other reported life events ( $25.2 \%$ of full sample, $35.6 \%$ of offender sample). In contrast, for the full sample, the most common sequence of life events among those experiencing all four $(n=360)$ is the in order and "normative" sequence of high school, steady job, marriage, and then children $(n=43,11.9 \%)$; for the offender sample with four life events $(n=96)$, the most common sequence is similar but children occur before marriage $(n=11,11.4 \%)$.

\section{Dominant Case Configurations}

The first step of a conjunctive analysis is to summarize all configurations or possible combinations of variable attributes within a data matrix. In this study, all offenders with each unique combination of the various life events, timing, and ordering is summed, depicted in a data matrix table of case configurations, and then the configurations are sorted from most to least common in order to determine the dominant case configurations. For example, the total number of offenders who experienced a steady job, marriage, and a child but not high school graduation, out of order (" 0 ") and off time (" 0 ") is summed as is every other possible unique variable combination. Thus, the data matrix could potentially depict 64 possible case configurations ( 2 categories for each life event, which equals $16 \times 2$ categories of timing $\times 2$ categories of order). However, Table 2 shows that among the 364 offenders, only 29 combinations are evident in the data. Moreover, after applying the minimum frequency rule of 5 (see [24]), we consider 12 of those 29 case configurations to be non-dominant, which leaves 17 dominant case configurations.

Among these dominant case configurations, one interesting revelation is that they all include having a steady job, and all but one includes being a parent. However, variation still exists for the number and type of life events experienced as well as the timing and ordering. Importantly, the two most common case configurations are ones with either three (a steady job, marriage, and a child) or all four life events that occur out of order and off time $(28.9 \%)$. In contrast, one of the least likely case configurations represents four life events, in order, and on time $(3.0 \%)$ with the least likely configuration being three life events (a steady job, marriage, and a child) in order and on time (1.6\%).

\section{Conjunctive Analysis of Case Configurations and Desistance}

\section{Main Effects}

The next phase of the analysis is to calculate the probability of desistance for each unique case configuration. We then sorted the case configurations based on their accompanying probability of desistance and inspected those above and below the mean and median. Table 3 displays each case configuration along with its probability of desistance. If desistance is "contextually invariant," we would expect the probability of 
Table 2 Dominant and non-dominant case configurations for offending sample $(n=364)$

\begin{tabular}{|c|c|c|c|c|c|c|c|}
\hline $\begin{array}{l}\text { High school } \\
\text { graduate }\end{array}$ & Steady job & Married & Parent & $\begin{array}{l}\text { Order } \\
(1=\text { in order })\end{array}$ & $\begin{array}{l}\text { Timing } \\
(1=\text { on time })\end{array}$ & $N$ & Proportion \\
\hline \multicolumn{8}{|c|}{ Dominant case configurations } \\
\hline 0 & 1 & 1 & 1 & 0 & 0 & 56 & 0.154 \\
\hline 1 & 1 & 1 & 1 & 0 & 0 & 49 & 0.135 \\
\hline 0 & 1 & 1 & 1 & 1 & 0 & 28 & 0.077 \\
\hline 0 & 1 & 0 & 1 & 1 & 1 & 26 & 0.071 \\
\hline 0 & 1 & 0 & 1 & 0 & 0 & 26 & 0.071 \\
\hline 1 & 1 & 1 & 1 & 1 & 0 & 24 & 0.066 \\
\hline 1 & 1 & 0 & 1 & 0 & 0 & 19 & 0.052 \\
\hline 1 & 1 & 0 & 1 & 1 & 1 & 15 & 0.041 \\
\hline 0 & 1 & 0 & 1 & 1 & 0 & 15 & 0.041 \\
\hline 1 & 1 & 1 & 1 & 0 & 1 & 12 & 0.033 \\
\hline 1 & 1 & 0 & 1 & 1 & 0 & 12 & 0.033 \\
\hline 0 & 1 & 0 & 1 & 0 & 1 & 12 & 0.033 \\
\hline 1 & 1 & 0 & 0 & 1 & 1 & 12 & 0.033 \\
\hline 1 & 1 & 1 & 1 & 1 & 1 & 11 & 0.030 \\
\hline 0 & 1 & 1 & 1 & 0 & 1 & 6 & 0.016 \\
\hline 1 & 1 & 0 & 1 & 0 & 1 & 6 & 0.016 \\
\hline 0 & 1 & 1 & 1 & 1 & 1 & 6 & 0.016 \\
\hline \multicolumn{8}{|c|}{ Non-dominant case configurations } \\
\hline 0 & 1 & 1 & 0 & 0 & 1 & 5 & 0.014 \\
\hline 1 & 1 & 1 & 0 & 1 & 1 & 3 & 0.008 \\
\hline 1 & 1 & 0 & 0 & 0 & 1 & 3 & 0.008 \\
\hline 0 & 1 & 1 & 0 & 1 & 1 & 3 & 0.008 \\
\hline 0 & 1 & 1 & 0 & 1 & 0 & 3 & 0.008 \\
\hline 1 & 1 & 1 & 0 & 0 & 0 & 2 & 0.005 \\
\hline 1 & 1 & 0 & 0 & 0 & 0 & 2 & 0.005 \\
\hline 1 & 1 & 0 & 0 & 1 & 0 & 2 & 0.005 \\
\hline 0 & 0 & 1 & 1 & 1 & 0 & 2 & 0.005 \\
\hline 0 & 1 & 1 & 0 & 0 & 0 & 2 & 0.005 \\
\hline 0 & 0 & 1 & 1 & 0 & 1 & 1 & 0.003 \\
\hline 1 & 0 & 0 & 1 & 0 & 1 & 1 & 0.003 \\
\hline
\end{tabular}

desistance for each case configuration to be similar to the sample mean probability of 0.715 (see [8]). However, this is not the case - the probability of desistance ranges from 0.167 to 1.00 (or without the 0.167 "outlier" the range is 0.577 to 1.00 ) indicating that indeed, "context matters."

We then examined the case configurations for evidence of main effects. First, there is evidence of an effect of dosage with the probabilities of desistance. All but one of the configurations above the mean (0.715) and median (0.733) have three or four life events. Further, this dosage effect seems to be driven by the presence of marriage with 
Table 3 Evidence of main effects of life course contexts on desistance

\begin{tabular}{|c|c|c|c|c|c|c|c|c|}
\hline $\begin{array}{l}\text { High } \\
\text { school } \\
\text { graduate }\end{array}$ & $\begin{array}{l}\text { Steady } \\
\text { job }\end{array}$ & Married & Parent & $\begin{array}{l}\text { Order } \\
(1=\text { in order })\end{array}$ & $\begin{array}{l}\text { Timing } \\
(1=\text { on time })\end{array}$ & $N$ & $\mathrm{P}($ desistance $)$ & \\
\hline 1 & 1 & 0 & 1 & 1 & 1 & 15 & 1.000 & \\
\hline 0 & 1 & 1 & 1 & 0 & 1 & 6 & 1.000 & \\
\hline 1 & 1 & 1 & 1 & 1 & 1 & 11 & 0.909 & \\
\hline 1 & 1 & 1 & 1 & 0 & 0 & 49 & 0.878 & \\
\hline 0 & 1 & 1 & 1 & 1 & 1 & 6 & 0.833 & \\
\hline 1 & 1 & 1 & 1 & 1 & 0 & 24 & 0.750 & \\
\hline 1 & 1 & 1 & 1 & 0 & 1 & 12 & 0.750 & \\
\hline 1 & 1 & 0 & 0 & 1 & 1 & 12 & 0.750 & \\
\hline 0 & 1 & 0 & 1 & 1 & 0 & 15 & 0.733 & MEDIAN $=0.733$ \\
\hline 0 & 1 & 1 & 1 & 0 & 0 & 56 & 0.714 & AVERAGE $=0.715$ \\
\hline 0 & 1 & 1 & 1 & 1 & 0 & 28 & 0.679 & \\
\hline 1 & 1 & 0 & 1 & 0 & 0 & 19 & 0.632 & \\
\hline 0 & 1 & 0 & 1 & 1 & 1 & 26 & 0.615 & \\
\hline 1 & 1 & 0 & 1 & 1 & 0 & 12 & 0.583 & \\
\hline 0 & 1 & 0 & 1 & 0 & 1 & 12 & 0.583 & \\
\hline 0 & 1 & 0 & 1 & 0 & 0 & 26 & 0.577 & \\
\hline 1 & 1 & 0 & 1 & 0 & 1 & 6 & 0.167 & \\
\hline
\end{tabular}

almost all of the case configurations lying above the mean and median probability of desistance including marriage as a life event and virtually none of the case configurations below the mean including marriage. Overall, we found little evidence that the other life events, the timing, or the ordering of these life events influence the probability of desistance as no emergent patterns are revealed when the data is sorted and analyzed. The next question we address is as follows: are there interactions between these life events, ordering, and timing in their influence on the probability of desistance?

\section{Interaction Effects}

Interaction effects can be ascertained by evaluating how outcome probabilities vary by certain characteristics (holding the others constant) [9, 24]. For example, the effect of timing may be more pronounced for cases with all four life events occurring in order compared to the effect of timing for respondents with only three life events occurring in order, indicating a two-way interaction among dosage and timing. To examine interaction effects, we sorted the data matrix by each life event, ordering, and timing and compared the probability of desistance among configurations that are similar in every way but one [9, 24]. For example, in order to assess whether timing has an interactive effect on desistance, we sorted the data by each life event and their order so that similar case configurations were aligned consecutively (i.e., cases with four life events occurring in order and on time are displayed next to cases with four life events in order and off time within the data matrix). As a result, a finding that case configurations differ by 
the contingency in question (e.g., timing) and feature differences in the probability of desisting indicates a potential interaction effect.

Table 4 shows the sorted case configurations such that within each configuration of life events and ordering, we vary timing. Interestingly, in these data, we find evidence of a three-way interaction between the number of life events, the timing, and the ordering of those events. For instance, we see from the dashed brackets that experiencing all four life events in order is more beneficial when it is also on time (e.g., the probability of desistance for four life events in order and on time is 0.909 compared to 0.750 for the configuration of four life events in order but off time and 0.750 for the configuration of four life events out of order but on time). In contrast, the configuration of four life events out of order and off time has a higher probability of desistance than those with only one or the other (i.e., in order but off time or out of order but on time) as indicated by the solid brackets. This pattern is also evident for those who experience three life events, especially when those three life events are high school, steady job, and being a parent (no marriage). Interestingly, there is no pattern in the probability of desistance when the configurations have only two life events; here, the timing and ordering of those events seem less influential when predicting desistance. This finding implies a possible three-way interaction in that for those with three and four life events, both timing and ordering are influential, yet these same variables appear far less relevant in predicting desistance for those with only two life events.

Table 4 Evidence of interaction effects on desistance from offending

\begin{tabular}{|c|c|c|c|c|c|c|c|}
\hline $\begin{array}{l}\text { High school } \\
\text { graduate }\end{array}$ & $\begin{array}{l}\text { Steady } \\
\text { job }\end{array}$ & Married & Parent & $\begin{array}{l}\text { Order } \\
(1=\text { in order })\end{array}$ & $\begin{array}{l}\text { Timing } \\
(1=\text { on time })\end{array}$ & $\mathrm{N}$ & $\mathrm{P}($ desistance $)$ \\
\hline 1 & 1 & 1 & 1 & 1 & 1 & 11 & 0.909 - ו \\
\hline 1 & 1 & 1 & 1 & 1 & 0 & 24 & 0.750 - \\
\hline 1 & 1 & 1 & 1 & 0 & 1 & 12 & $0750 \quad \mathrm{I}$ \\
\hline 1 & 1 & 1 & 1 & 0 & 0 & 49 & $0.878^{-1}$ \\
\hline 1 & 1 & 0 & 1 & 1 & 1 & 15 & 1.000 \\
\hline 1 & 1 & 0 & 1 & 1 & 0 & 12 & 0.583 \\
\hline 1 & 1 & 0 & 1 & 0 & 1 & 6 & 0.167 \\
\hline 1 & 1 & 0 & 1 & 0 & 0 & 19 & 0.632 \\
\hline 0 & 1 & 1 & 1 & 1 & 1 & 6 & 0.833 \\
\hline 0 & 1 & 1 & 1 & 1 & 0 & 28 & 0.679 \\
\hline 0 & 1 & 1 & 1 & 0 & 1 & 6 & 1.000 \\
\hline 0 & 1 & 1 & 1 & 0 & 0 & 56 & 0.714 \\
\hline 0 & 1 & 0 & 1 & 1 & 1 & 26 & 0.615 \\
\hline 0 & 1 & 0 & 1 & 1 & 0 & 15 & 0.733 \\
\hline 0 & 1 & 0 & 1 & 0 & 1 & 12 & 0.583 \\
\hline 0 & 1 & 0 & 1 & 0 & 0 & 26 & 0.577 \\
\hline 1 & 1 & 0 & 0 & 1 & 1 & 12 & 0.750 \\
\hline
\end{tabular}


Table 5 Logistic regression models of the main effects and interaction between dosage, timing, and ordering of life events on desistance $(n=364)$

\begin{tabular}{llll}
\hline & $\begin{array}{l}\text { Model 1 } \\
\text { OR (se) }\end{array}$ & $\begin{array}{l}\text { Model 2 } \\
\text { OR (se) }\end{array}$ & $\begin{array}{l}\text { Model 3 } \\
\text { OR (se) }\end{array}$ \\
\hline $\begin{array}{llll}\text { Timing } \\
\text { Order }\end{array}$ & $1.11(0.28)$ & $1.11(0.28)$ & $0.87(0.23)$ \\
Dosage & $1.22(0.35)$ & $1.21(0.35)$ & $0.76(0.25)$ \\
3 life events & & & $0.93(0.30)$ \\
4 life events & - & $1.42(0.41)$ & $1.89(0.76)$ \\
DosagexTimingxOrder & - & $2.58(0.96)^{*}$ & $13.90(15.19)^{*}$ \\
1 & - & - & $3.29(3.75)$ \\
2 & - & - & - \\
High School & $1.55(0.42)$ & - & - \\
Steady Job & $1.04(1.23)$ & - & - \\
Married & $1.89(0.49)^{*}$ & - & - \\
Parent & $1.03(0.44)$ & - & \\
\hline
\end{tabular}

Note: All models control for gender and criminal propensity

${ }^{* *} p<0.01,{ }^{*} p<0.05, \wedge p<0.10$,

\section{Logistic Regression}

In order to quantitatively test for the potential main and moderating effects revealed in the CACC while controlling for key predictors of offending (i.e., gender and criminal propensity), we now shift our unit of analysis from case configurations to individuals and employ the more traditional approach of logistic regression using the dichotomous indicator of desistance as our dependent variable. ${ }^{9}$ To understand both the main effects as well as the interactive effects, we conduct several models. First, we include each life event separately along with timing, ordering, and the controls of gender and criminal propensity. Female is coded as "1," and criminal propensity is a continuous index drawn from eight dichotomous variables (see Appendix A). Table 5 (model 1) shows that with all of the life events in the model, being married significantly increases the likelihood of desistance $(\mathrm{OR}=1.89, p<0.05)$, yet there are no main effects for the other life events or for timing or ordering.

We next conduct a logistic regression model that directly estimates the impact of dosage along with timing and ordering. Here, dosage is defined as a trichotomous variable with " 0 " indicating experiencing two life events, " 1 " indicating experiencing three life events, and " 2 " indicating experiencing all four life events (see model 2, Table 5). This model shows that there is a main effect of dosage with those experiencing four life events being over twice as likely to desist than those with two life events $(\mathrm{OR}=2.58, p<0.05)$, yet there is no significant difference between experiencing three events and experiencing

\footnotetext{
${ }^{9}$ In a replication of the analyses using hierarchical linear modeling, which provides a developmental model that assumes a continuous distribution of trajectories, the findings of a main effect of dosage and a three-way interaction effect of dosage, timing, and ordering remain.
} 
either two or four life events. Model 3 then introduces the three-way interaction term between dosage, timing, and ordering. This model reveals that these three contingencies in combination significantly impact the probability of desistance.

To visualize and substantively interpret the three-way interactions, we estimate and graph the average marginal effects of having one's life events be in order on the predicted probability of desistance separately for those whose life events are on time and those whose life events are off time. We do this separately for those experiencing two, three, and four life events to best convey the three-way interaction. As depicted in Fig. 2, for those who experience two life events, there is no significant effect of order among those who experienced those life events on time or off time - as indicated by the error bars overlapping the zero axis. This is in contrast to those who experienced three life events where we see that having one's life events occur in order significantly increases the probability of desistance if those life events are also on time but not if they are off time. This same pattern is evident among those experiencing four life events, although this effect does not reach statistical significance.

\section{Discussion}

The Conjunctive Analysis of Case Configurations (CACC) was introduced to criminology several years ago and has been employed to understand situations and criminal events. However, as illustrated here, the benefits of this method are extensive when applied to life course criminology as it can systematically and purposefully guide the quantitative researcher to better understand the complexity of the unfolding of life events over time. In essence, CACC provides a method to re-focus our attention on what Laub calls descriptive quantitative criminology ([15]: 423) emphasizing the necessity to understand the basics of a phenomena under study before moving to more complicated statistical techniques. Indeed, in this study, we combined the method of CACC, which provides a rich descriptive understanding of the number, timing, and ordering of life events, with the more traditional approach of regression, which provided a formal test of statistical significance. As a result, several key findings emerged.

First, researchers have posited that as the generations advance, the ideas of a "normative sequence" or on time events are in danger of becoming outdated [35]. Therefore, a wide variety of ordering among life events or "individualization" may now be "normative". Indeed, African Americans may be the most likely to see extreme individualization as this group is less likely to marry, more likely to marry later, more likely to be unemployed, more likely to have kids out of wedlock, and more likely to drop out of high school than whites (e.g., [1, 41]; see also, [35]). In this study, we see evidence of individualization in the fact that there were 91 unique sequences of events for the cohort as a whole and 67 unique sequences of events for the offender subsample. Moreover, the most common case configurations were ones that had either three or four life events, out of order, and off time while the least likely case configuration represented those who experience three or four life events, in order, and on time (i.e., the supposed "normative" or socially expected configuration). This level of individualization is even more striking given that these individuals were experiencing their life events in the 1980s and 1990s. Thus, it is likely that more recent cohorts may evidence even more individualization. 

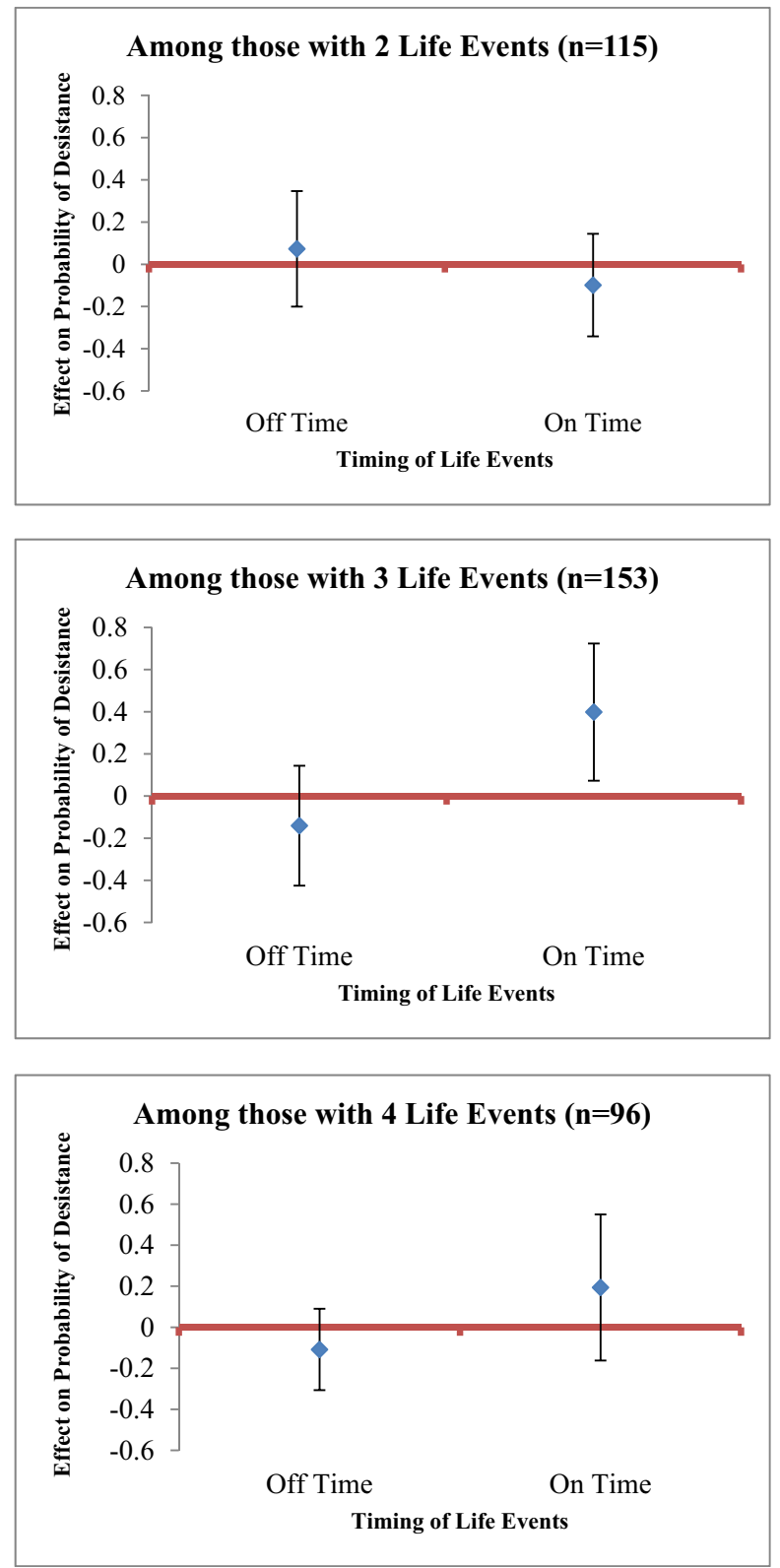

Fig. 2 Average marginal effects of "in order" on the predicted probability of desistance for "on time" vs. "off time" life events, by number of life events

Second, the CACC analysis revealed that the relationship between the dominant configurations and the configurations that are most predictive of desistance are quite different. For instance, among the least likely case configurations is the four life events, in order, and on time configuration, which was associated with one of the highest probabilities of desistance. Therefore, although experiencing that "normative" configuration may 
be rare, as was the case in this sample, its potential effect on desistance is evident. This finding has potential implications for criminal justice and social policy as it may be that combined programs that consider multiple tethers to conventional society (e.g., job programs, GED programs, strengthening families, family planning initiatives) that are timed and ordered may be most effective in facilitating desistance.

Finally, beyond allowing for descriptive quantitative criminology in the form of understanding the "normative" sequences of events in this sample, CACC also identified a main effect of dosage as well as a potential moderating effect, both of which were confirmed as statistically significant with the logistic analysis. Thus, these analyses reveal interesting direct and indirect relationships between three contextual factors of life events; yet, without first analyzing the data using CACC, any traditional regression analysis would have been ill-informed and would have resembled more of a "fishing" expedition than purposeful research as achieved with the use of CACC. Thus, beyond descriptive quantitative criminology, the CACC method allows for enhanced substantive knowledge in combination with formal statistical testing as well.

\section{Limitations of CACC}

Although CACC has a number of strengths, like all methods, it also has limitations, and we would be remiss if we did not at least discuss these briefly. First, CACC relies on investigations of binary or limited categorical outcomes, making it less useful for investigations involving continuous level indicators or variations of an outcome, such as rates of offending, rather than the presence or absence of an outcome. Second, these models can quickly become very complex. For instance, complexity increases as the number of indicators in the configurations increases or if multiple indicators are ordinal rather than nominal. One technique to reduce the number of potential indicators is to conduct preliminary statistical tests or algorithms to identify key predictors to include in the model $[23,25]$. However, this preliminary identification of effects may mask important relationships and compromises a core strength of CACC, which is its exploratory nature of the interrelationships of indicators. Third, a by-product of increased complexity is the need for larger samples to ensure a sufficient number of cases in each of the multiple configurations. For example, in this study the small sample size of women offenders $(n=101)$ precluded a conjunctive analysis of case configurations by gender given the low frequencies of many case configurations. Moreover, the small sample size of high-rate persisters $(n=29)$ and desisters $(n=34)$ precluded an analysis between the high-rate and low-rate offenders.

Although not a limitation per se, one additional cautionary note in employing CACC is that the application must be theoretically driven. Thus, in one sense, CACC can be used to uncover potential relationships important to life course criminologists. However, like other methodologies introduced to developmental research, the method should not be divorced from theory but instead be informed by the substantive understanding of the phenomenon at hand.

\section{Additional Applications to Life Course Criminology}

The current application of CACC represents only one of many life course research questions where this method could prove helpful. For instance, while the current paper 
investigates some of the sources of variability - the number, timing, and ordering of life events - there are additional areas that center on the contextual variance of offending over the life course. For instance, there may be interactions between life events and individual factors, such as "chronic strains," which are associated with variability in the response to a life event $[28,38]$. Indeed, social circumstances, such as living in a dangerous neighborhood and experiencing discrimination and financial hardship, have repeatedly been found in the stressful life event literature to impact health [38]. However, possible interactions have yet to be adequately examined in the life course literature. Thus, CACC could provide an important and useful tool of descriptive quantitative criminology in revealing the presence and nature of these potential moderating effects.

Another possible application to developmental and life course criminology may be in the realm of risk and protective factors. For instance, there is ongoing research as to whether risk and protective factors are additive or interactive (i.e., direct or buffering) [20]. One application of CACC might be to examine the case configurations of a number of risk and protective factors and explore the data matrix of those case configurations and offending (or non-offending) outcomes. The ability of CACC to identify both main effects as well as interactive effects could prove very useful when examining the role of risk and protective factors in predicting the "off-diagonals" (i.e., high risk configurations with low probabilities of offending as well as low risk configurations with high probabilities of offending). This descriptive quantitative step could greatly enhance our understanding of risk and protective factors and their role in delinquency prevention. Indeed, questions about how age interacts with risk and protective factors or explorations into the individual $\times$ situational elements inherent in criminal activity represent other areas that could prove fruitful avenues to unpack the complexities inherent in life course research.

Finally, there are several areas of future research that draw directly from the current analysis. Given that the sample used in this study comprises African Americans from one neighborhood who were born in the early 1960 s, future research is needed on individualization of the life course as well as the importance of dosage, timing, and ordering of events among general population samples, among diverse populations, and/ or among more contemporary samples. Another limitation of this study that future work could address is the issue of gender in predicting life course outcomes. Although we were able to control for gender in the multivariate model, we could not include it in the case configuration analysis given the small number of female offenders. Thus, given that the number of life events as well as the timing and ordering of those events may differ by gender, future studies with larger samples sizes should investigate the role of gender in these potential contingencies in desistance outcomes.

\section{Conclusion}

Overall, this study sought to achieve three separate goals. First, we sought to examine the importance of the number, timing, and ordering of life events, alone and in combination, to explain the heterogeneity in desistance outcomes. Second, we sought to illustrate how CACC can be a powerful tool to address this type of life course question. Third, we sought to introduce examples of additional life course research questions that could benefit from using CACC. In sum, we recommend that CACC be 
added to developmental and life course criminology researchers' methodological tool box as its use has the potential to inform both life course theory as well as policy.

Acknowledgments This research was supported in part by NIDA grant R01 DA033999 and by the Harry Frank Guggenheim Foundation. We would like to thank Margaret Ensminger and Kerry Green for their comments on an earlier draft of this paper.

\section{References}

1. Dixon, P. (2009). Marriage among African Americans: what does the research reveal? Journal of African American Studies, 13, 29-46.

2. Doherty, E., \& Ensminger, M. E. (2014). Do the adult criminal careers of African Americans fit the "facts"? Journal of Criminal Justice, 42(6), 517-526.

3. Eggleston, E. P., Laub, J. H., \& Sampson, R. J. (2004). Methodological sensitivities to latent class analysis of long-term criminal trajectories. Journal of Quantitative Criminology, 20(1), 1-26.

4. Elder, G. H. (1985). Life course dynamics: trajectories and transitions, 1968-1980. Ithaca: Cornell University Press.

5. Elder, G. H. (1998). The life course as developmental theory. Child Development, 69(1), 1-12.

6. George, L. K. (1993). Sociological perspectives on life transitions. Annual Review of Sociology, 19, 353-373.

7. Giordano, P. C., Cernkovich, S. A., \& Rudolph, J. L. (2002). Gender, crime, and desistance: toward a theory of cognitive transformation. American Journal of Sociology, 107(4), 990-1064.

8. Hart, T. C., Hart, J. L., \& Miethe, T. D. (2013). Situational context of student bullying victimization and reporting behavior: a conjunctive analysis of case configurations. Justice Research and Policy, 15(2), 43-73.

9. Hart, T. C., \& Miethe, T. D. (2009). Self-defensive gun use by crime victims a conjunctive analysis of its situational contexts. Journal of Contemporary Criminal Justice, 25(1), 6-19.

10. Hart, T. C., \& Miethe, T. D. (2011). Violence against college students and its situational contexts: prevalence, patterns, and policy implications. Victims and Offenders, 6(2), 157-180.

11. Hart, T. C., Miethe, T. D., \& Regoeczi, W. C. (2014). Contextualizing sentencing disparities: using conjunctive analysis of case configurations to identify patterns of variability. Criminal Justice Studies, 27(4), 344-361.

12. Hogan, D. P. (1978). The variable order of events in the life course. American Sociological Review, 43, 573-586.

13. Hogan, D. P. (1980). The transition to adulthood as a career contingency. American Sociological Review, $45,261-276$.

14. Jones, B. L., Nagin, D. S., \& Roeder, K. (2001). A SAS procedure based on mixture models for estimating developmental trajectories. Sociological Methods \& Research, 29(3), 374-393.

15. Laub, J. H. (2010). Nurturing the Journal of Quantitative Criminology through late childhood: retrospective memories (distorted?) from a former editor. Journal of Quantitative Criminology, 26(4), 421-424.

16. Laub, J.H., Nagin, D.S., \& Sampson, R.J. (1998). Trajectories of change in criminal offending: good marriages and the desistance process. American Sociological Review, 225-238.

17. Laub, J. H., \& Sampson, R. J. (2003). Shared beginnings, divergent lives: delinquent boys to age 70. Cambridge: Harvard University Press.

18. Leclerc, B., \& Cale, J. (2015). Weapon use and sexual abuse outcomes: a multivariate and conjunctive analysis of sexual offenses against women. Security Journal, 28(1), 54-70.

19. Lockwood, K., Hart, T. C., \& Stewart, A. (2015). First nations peoples and judicial sentencing: main effects and the impact of contextual variability. British Journal of Criminology, 55(4), 769-789.

20. Lösel, F., \& Farrington, D. P. (2012). Direct protective and buffering protective factors in the development of youth violence. American Journal of Preventive Medicine, 43(251), S8-S23.

21. Macmillan, R. (2005). The structure of the life course: classic issues and current controversies. Advances in Life Course Research, 9, 3-24.

22. Macmillan, R., \& Eliason, S. R. (2003). Characterizing the life course as role configurations and pathways. In J. T. Mortimer \& M. J. Shanahan (Eds.), Handbook of the life course (pp. 529-554). New York: Springer.

23. Mieczkowski, T., \& Beauregard, E. (2010). Lethal outcome in sexual assault events: a conjunctive analysis. Justice Quarterly, 27(3), 332-361. 
24. Miethe, T. D., Hart, T. C., \& Regoeczi, W. C. (2008). The conjunctive analysis of case configurations: an exploratory method for discrete multivariate analyses of crime data. Journal of Quantitative Criminology, 24(2), 227-241.

25. Miethe, T. D., \& Regoeczi, W. C. (2004). Rethinking homicide: exploring the structure and process underlying deadly situations. New York: Cambridge University Press.

26. Nagin, D. S. (1999). Analyzing developmental trajectories: a semiparametric, group-based approach. Psychological Methods, 4(2), 139-157.

27. Nagin, D. (2005). Group-based modeling of development. Cambridge: Harvard University Press.

28. Pearlin, L.I., Menaghan, E.G., Lieberman, M.A., \& Mullan, J.T. (1981). The stress process. Journal of Health and Social Behavior, 337-356.

29. Piquero, A. R., Blumstein, A., Brame, R., Haapanen, R., Mulvey, E. P., \& Nagin, D. S. (2001). Assessing the impact of exposure time and incapacitation on longitudinal trajectories of criminal offending. Journal of Adolescent Research, 16(1), 54-74.

30. Ragin, C.C. (2013). New directions in the logic of social inquiry. Political Research Quarterly, 171-174.

31. Rennison, C. M. (2010). An investigation of reporting violence to the police: a focus on Hispanic victims. Journal of Criminal Justice, 38(4), 390-399.

32. Rennison, C. M., DeKeseredy, W. S., \& Dragiewicz, M. (2013). Intimate relationship status variations in violence against women urban, suburban, and rural differences. Violence Against Women, 19(11), 1312-1330.

33. Rindfuss, R. R., Swicegood, C. G., \& Rosenfeld, R. A. (1987). Disorder in the life course: how common and does it matter? American Sociological Review, 52(6), 785-801.

34. Sampson, R. J., \& Laub, J. H. (1993). Crime in the making: pathways and turning points through life. Cambridge: Harvard University Press.

35. Shanahan, M. J. (2000). Pathways to adulthood in changing societies: variability and mechanisms in life course perspective. Annual Review of Sociology, 26, 667-692.

36. Siennick, S. E., \& Osgood, D. W. (2008). A review of research on the impact on crime of transitions to adult roles. In A. M. Liberman (Ed.), The long view of crime: a synthesis of longitudinal research (pp. 161-187). New York: Springer.

37. Theobald, D., \& Farrington, D. P. (2009). Effects of getting married on offending results from a prospective longitudinal survey of males. European Journal of Criminology, 6(6), 496-516.

38. Thoits, P. A. (2010). Stress and health major findings and policy implications. Journal of Health and Social Behavior, 51(1), S41-S53.

39. Uggen, C. (2000). Work as a turning point in the life course of criminals: a duration model of age, employment, and recidivism. American Sociological Review, 529-546.

40. Umberson, D. (1987). Family status and health behaviors: Social control as a dimension of social integration. Journal of Health and Social Behavior, 28, 306-319.

41. Wilson, W. J. (1987). The truly disadvantaged: the inner city, the underclass, and public policy. Chicago: University of Chicago Press. 